\title{
Modeling of Antenna for Deep Target Hydrocarbon Exploration
}

\author{
Nadeem Nasir ${ }^{1,{ }^{*}}$, Noorhana Yahya ${ }^{2}$, Hasnah Mohd Zaid ${ }^{2}$, Afza Shafie $^{2}$, and Norhisham Hamid ${ }^{1}$ \\ ${ }^{1}$ Electrical and Electronic Engineering Department, Universiti Teknologi PETRONAS, \\ 31750 Bandar Seri Iskandar, Tronoh, Perak, Malaysia \\ ${ }^{2}$ Fundamental and Applied Science Department, Universiti Teknologi PETRONAS, \\ 31750 Bandar ${ }_{*}$ Seri Iskandar, Tronoh, Perak, Malaysia \\ nadeemntu@hotmail.com
}

\begin{abstract}
Nowadays control source electromagnetic method is used for offshore hydrocarbon exploration. Hydrocarbon detection in sea bed logging (SBL) is a very challenging task for deep target hydrocarbon reservoir. Response of electromagnetic (EM) field from marine environment is very low and it is very difficult to predict deep target reservoir below $2 \mathrm{~km}$ from the sea floor. This work premise deals with modeling of new antenna for deep water deep target hydrocarbon exploration. Conventional and new EM antennas at $0.125 \mathrm{~Hz}$ frequency are used in modeling for the detection of deep target hydrocarbon reservoir. The proposed area of the seabed model $\left(40 \mathrm{~km}^{\prime} 40 \mathrm{~km}\right)$ was simulated by using CST (computer simulation technology) EM studio based on Finite Integration Method (FIM). Electromagnetic field components were compared at 500m target depth and it was concluded that Ex and $\mathrm{Hz}$ components shows better resistivity contrast. Comparison of conventional and new antenna for different target depths was done in our proposed model. From the results, it was observed that conventional antenna at $0.125 \mathrm{~Hz}$ shows $70 \%, 86 \%$ resistivity contrast at target depth of $1000 \mathrm{~m}$ where as new antenna showed $329 \%$, $355 \%$ resistivity contrast at the same target depth for $\mathrm{Ex}$ and $\mathrm{Hz}$ field respectively. It was also investigated that at frequency of $0.125 \mathrm{~Hz}$, new antenna gave $46 \%$ better delineation of hydrocarbon at $4000 \mathrm{~m}$ target depth. This is due to focusing of electromagnetic waves by using new antenna. New antenna design gave $125 \%$ more extra depth than straight antenna for deep target hydrocarbon detection. Numerical modeling for straight and new antenna was also done to know general equation for electromagnetic field behavior with target depth. From this numerical model it was speculated that this new antenna can detect up to $4.5 \mathrm{~km}$ target depth. This new EM antenna may open new frontiers for oil and gas industry for the detection of deep target hydrocarbon reservoir (HC).
\end{abstract}

Copyright (C) 2017Journal of Mechanical Engineering Science and Technology

All rights reserved

Keywords: Bentonite, Portland cement, Strength of moulding sand

\section{Introduction}

Sea bed logging is an application of control source electromagnetic method which is used to locate an oil reservoir beneath the sea floor by measuring electromagnetic fields [1-4]. In typical control source method a horizontal electric dipole antenna is towed by a surface vessel at a short distance $30 \mathrm{~m}$ above from the sea floor [5-7]. Dipole antenna transmits very low frequency electromagnetic waves with frequency ranges from $0.25 \mathrm{~Hz}-10 \mathrm{~Hz}$ due to low frequency transmitted energy propagates down through the subsurface [8-10]. Low frequency electromagnetic waves attenuate more in the conductive layer and less in the resistance layer due to the skin depth. In a large resistive layer such as hydrocarbon electromagnetic energy flows along the reservoir (described as guided wave) is detected by the stationary sea floor electric or magnetic field detectors which are deployed on the sea floor. Control source electromagnetic method depends on the resistivity of the hydrocarbon and surrounding sediments. Hydrocarbon in the sea bed has resistivity of few tens to hundred ohm meter $(30 \Omega \mathrm{m}-500 \Omega \mathrm{m})$, sea water $(0.5 \Omega \mathrm{m}-2 \Omega \mathrm{m})$ while all other layers including sediments in the sea have resistivity $(1 \Omega \mathrm{m}-2 \Omega \mathrm{m})$ [11-17]. In deep water the air wave effect is negligible so the wave guided back from the hydrocarbon can predict the presence of hydrocarbon [18]. Target depth is also very important in sea bed logging. Frequency and offset plays an important role to determine target depth. Shallow targets shows measurable response at near offset with high frequency where as deep targets at large offset with low frequency. G. Michael Hoversten reports that simulated oil-water contact at $2 \mathrm{~km}$ depth below the sea floor shows a response below the expected noise levels. The resistivity model in which maximum target depth response measured was $3 \mathrm{~km}$ for $8 \mathrm{~km}$ offset [19]. Multiple frequency range of electromagnetic waves is used to improve control source electromagnetic data for deep target hydrocarbon reservoir. 
Deep target having variable size and depth can cause the risk factor so high and low frequency reduces this risk factor. Deep water field survey in Nigeria two fundamental frequencies $(0.05 \mathrm{~Hz}$ and $0.25 \mathrm{~Hz})$ with higher frequency are used which shows very promising survey results. For shallow target depth $0.25 \mathrm{~Hz}$ frequency and the first two harmonics is useful to detect the thin resistive hydrocarbon reservoir. Low frequency $(0.05 \mathrm{~Hz})$ data provide useful information about $2 \mathrm{~km}$ resistivity background model. This wide range of multiple frequencies is used to reduce the drilling risk factor [20]. Direct detection of hydrocarbon which is deeply buried can be done by subsea EM sounding technique. Survey was done across TWGP, Norway offshore and they found the target at the depth of $1100 \mathrm{~m}$ below the sea floor was reported [21]. Transmitter height changing above the sea floor was investigated in a noise model and also included the data which create uncertainty by changing the transmitter height. Inversion of the data with multilayers and four layers models was done. It was observed that this model can detect the resistive layer at a depth of 1500$1600 \mathrm{~m}$ below the sea floor for control source CSEM electromagnetic method where as $2 \mathrm{~km}$ depth for seismic method [22]. Propagation of electromagnetic (EM) waves travelling in seawater can be predicted by using Maxwell's equations. If the propagating of electromagnetic wave in the $y$ direction then it can be described in terms of the electric field strength Ex and the magnetic field strength $\mathrm{Hz}$ [23].

$$
\begin{aligned}
& E_{X}=E_{0} \exp (j \omega t-\gamma y) \\
& H_{\alpha}=H_{0} \exp (j \omega t-\gamma y) \\
& \gamma=j \omega \sqrt{s \mu-j \frac{\sigma_{A}}{\omega}}=\alpha+j \beta
\end{aligned}
$$

Where $(\gamma)$ is the propagation constant, $(\varepsilon)$ permittivity, $(\mu)$ permeability, $(\sigma)$ conductivity, $\alpha$ attenuation factor, $\beta$ phase factor and $\omega=2 \pi f$ the angular frequency as given in equation (3). Electromagnetic wave propagation can be described by a wave number $\mathrm{K}$ as given in equation 4.

$$
K=\omega \sqrt{\mu \omega+\frac{i \mu \omega}{\omega}}=\frac{\omega}{c_{p}}+\frac{1}{b}
$$

Where $\mathrm{k}$ is the wave number and $\mathrm{i}=\mathrm{O}-1$ is the complex number, $\mathrm{Cp}$ phase velocity and $\square$ is the skin depth. First term in equation (4) inside the square root represent the displacement current and second term represent conduction current in Maxwell's equation.

Numerical model is a very important to know the location hydrocarbon in sea bed logging. It can provide the information about the target depth at which target depth the electromagnetic wave signal provide information about hydrocarbon reservoir [24].

Table 1. Simulated model parameters with different resistive layers (air, sea water, overburden and under burden)

\begin{tabular}{rccccc}
\hline $\begin{array}{c}\text { Target } \\
\text { depth }\end{array}$ & $\begin{array}{c}\text { Air } \\
\text { thickness }\end{array}$ & $\begin{array}{c}\text { Under } \\
\text { burden }\end{array}$ & $\begin{array}{c}\text { Hydro- } \\
\text { carbon }\end{array}$ & Sea Water depth & Frequency \\
\hline $\mathbf{m})$ & $(\mathbf{m})$ & $\mathbf{( m )}$ & & & $(\mathbf{H z})$ \\
\hline & & & & 2000 & 0.125 \\
\hline & 500 & 4500 & 100 & 2000 & 0.125 \\
\hline & 500 & 4250 & 100 & 2000 & 0.125 \\
\hline & 500 & 4000 & 100 & 2000 & 0.125 \\
\hline & 500 & 3750 & 100 & 2000 & 0.125 \\
\hline & 500 & 3500 & 100 & 2000 & 0.125 \\
\hline 4500 & 500 & 3250 & 100 & 2000 & 0.125 \\
\hline
\end{tabular}


Table 2. Relative permittivity, conductivity values of air, sea water Overburden/under burden and hydrocarbon

\begin{tabular}{ccccc}
\hline Material parameters & Air & Sea water & $\begin{array}{c}\text { Under Burden/ } \\
\text { Over Burden }\end{array}$ & Hydrocarbon \\
\hline Conductivity & 1.006 & 80 & 30 & 4 \\
\hline Relative Pemittivity & $1.0 \mathrm{e}-11$ & 4 & 1.5 & 0.001 \\
\hline Thermal conductivity & 0.024 & 0.593 & 2 & 0.492 \\
\hline Density & 1.293 & 1025 & 2600 & 900 \\
\hline
\end{tabular}

This work premise deals with the study of electromagnetic field components, conventional and new antenna electromagnetic field comparison for deep target hydrocarbon reservoir detection. New antenna electric field data of different curvatures is used for numerical model to know the exact target depth with this new antenna design.

\section{Methods.}

We use CST (Computer simulation technology) software for finite integration method (FIM). Computer simulation technology (CST) is used to discritize each Maxwell's equations at low frequency to investigate the resistivity contrast.Forfinite integration technique,Computer simulation technology software is used as a tool for low frequency to solve any problem. FIM was used to detect deep target hydrocarbon below $3000 \mathrm{~m}$ from seafloor by using CST software. CST software was used to detect deep target hydrocarbon between $1000 \mathrm{~m}$ to $400 \mathrm{~m}$ underneath seabed. Model area was assigned as $40^{\prime} 40 \mathrm{~km}$ to replicate the real seabed environment with various target positions. Environment with and without hydrocarbon were also prepared for comparison purpose later. There were few steps involved in generating the CST simulated model. First step was to set parameters for aluminium antenna. In this case we used length of $270 \mathrm{~m}$, frequency of $0.125 \mathrm{~Hz}$ and current of $1250 \mathrm{~A}$. Second step was to set parameters for the model. Airthickness was set as $500 \mathrm{~m}$, sea water depth of $2000 \mathrm{~m}$, overburden thickness of $1000 \mathrm{~m}$, hydrocarbon thickness of $100 \mathrm{~m}$ and under burden with their different conductivities and permeability values (Table 2). Thickness of the overburden was increased as the target depth varied gradually (every $250 \mathrm{~m}$ ) from $500 \mathrm{~m}$ to $5000 \mathrm{~m}$. Third step was to apply electric boundary conditions (Table 1). Fourth step was to run low frequency full wave solver to simulate sea bed model. The final step was post processing to generate the simulated data for results analysis at different target depths. Maxwell's equations for magnetic and electric fields are used as a code in the software to get electric and magnetic field response with and without HC. Schematic diagram of proposed seabed model with CST simulated model is shown in Figure 1.
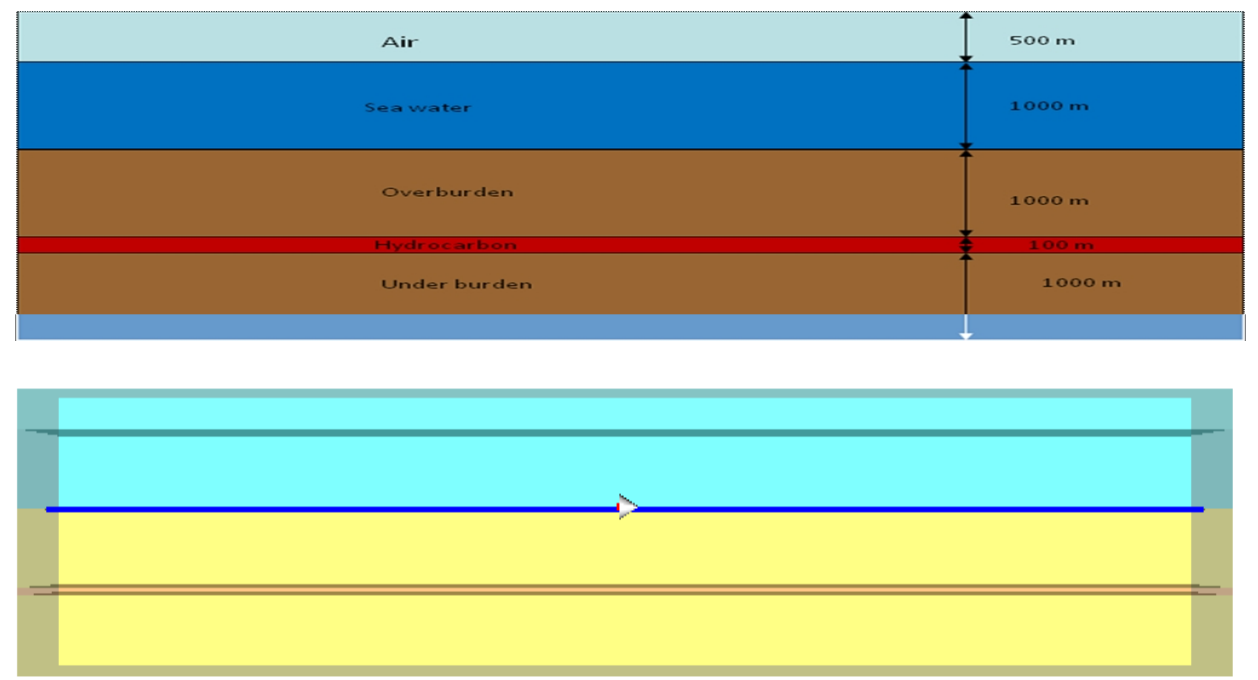

Fig. 1. (a) Schematic diagram of proposed model and (b) CST simulated model 


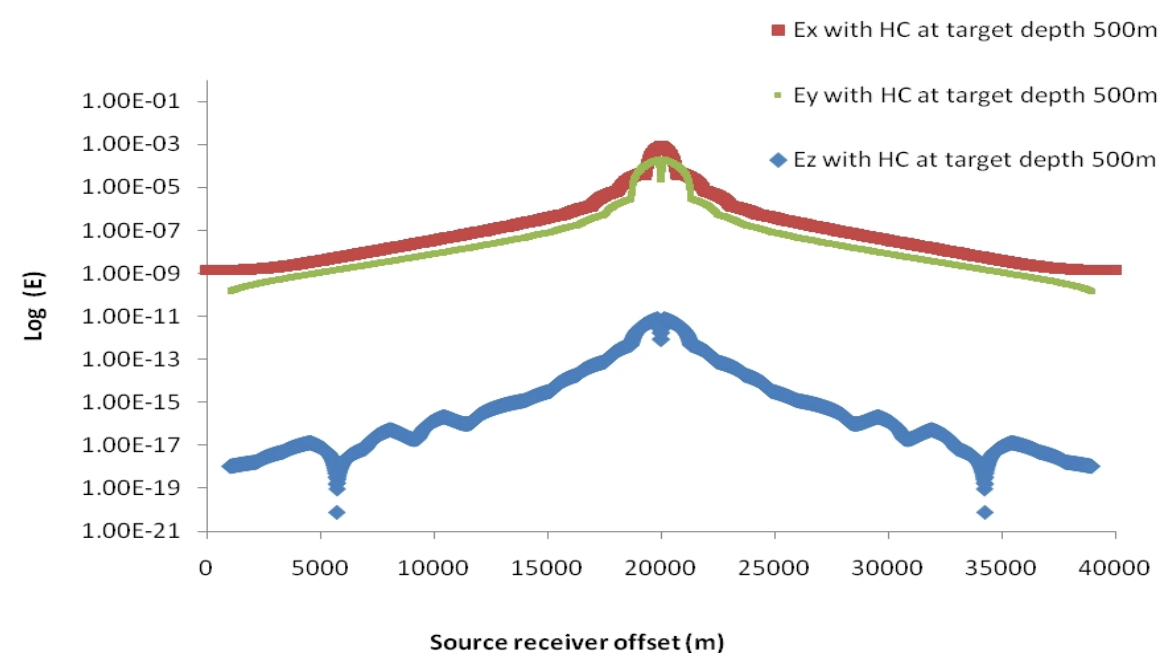

Fig. 2. Comparison of E-filed components (Ex, Ey, Ez) response at 500m target depth

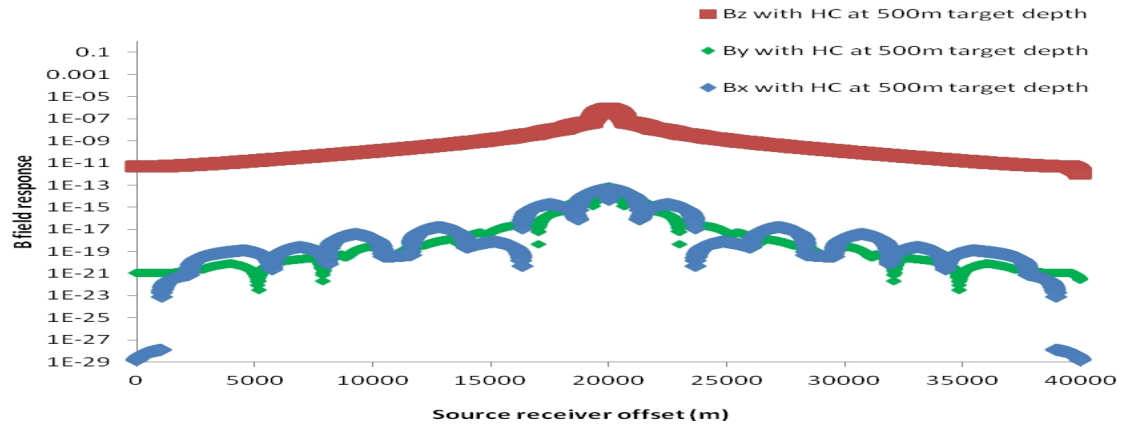

Fig. 3. Comparison of B-filed components (Bx, By, Bz) response at 500m target depth

\section{Results and discussion.}

Electromagnetic field components response from hydrocarbon reservoir in sea bed logging is very important to show better resistivity contrast. In sea bed logging both electric and magnetic field sensors are placed on the sea floor to record the electromagnetic field data. Electromagnetic field data consists of three components i.e. ( $x, y$, and $z$ ). Choice of the electromagnetic field components depends on the electromagnetic waves propagation. All three components of electric field response were measured with conventional HED antenna within the proposed area $(40 \mathrm{~km} \mathrm{x}$ $40 \mathrm{~km})$. Components study was done in deep water $(2000 \mathrm{~m})$ where no air waves effect take place. Comparison of E-field components is given in Figure 2. Ex component shows better E field response at $500 \mathrm{~m}$ target depth as compared to Ey and Ez.

Magnetic field components comparison was also done to know which component gave high magnetic field response with the presence of hydrocarbon reservoir. Magnetic field strength is although lower than the electric field strength but it is also very important for hydrocarbon prediction but only for shallow target where as for deep target the signal strength is very low which cannot be able to predict the presence of hydrocarbon reservoir. Magnetic field comparison is given in Figure 3. Bz component gave higher magnetic field response with the presence of hydrocarbon reservoir at $500 \mathrm{~m}$ depth. $\mathrm{H}$ - field response was also analyzed at $500 \mathrm{~m}$ target depth is given in Figure 4. H-field response of all three components was recorded and plotted to know which component gave higher response. $\mathrm{Hz}$ component shows better response with the presence of hydrocarbon reservoir than $\mathrm{Hx}$ and $\mathrm{Hy}$. Selection of E, B and $\mathrm{H}$ field components was done and it was conclude that $\mathrm{Ex}, \mathrm{Bz}$ and $\mathrm{Hz}$ gave better delineation of hydrocarbon reservoir at $500 \mathrm{~m}$ target depth. 
Finally $\mathrm{Ex}, \mathrm{Bz}$ and $\mathrm{Hz}$ electromagnetic field components were plotted as given Figure 5. From these results, it was observed that the Ex and $\mathrm{Hz}$ components gave better delineation of hydrocarbon reservoirs according to Maxwell's equations; if the electromagnetic wave is propagating in y direction then $\mathrm{Ex}$ and $\mathrm{Hz}$ components gave better delineation of hydrocarbon reservoirs [25]. These two components were chosen for deep target hydrocarbon detection with straight and new antenna.

\section{A. Straight antenna MVO Results}

Straight antenna magnitude verses offset data was plotted to compare with new antenna in full scale sea bed logging environment. Conventional antenna and new antenna length, frequency and model were kept same to check the performance of new antenna for deep water-deep target.

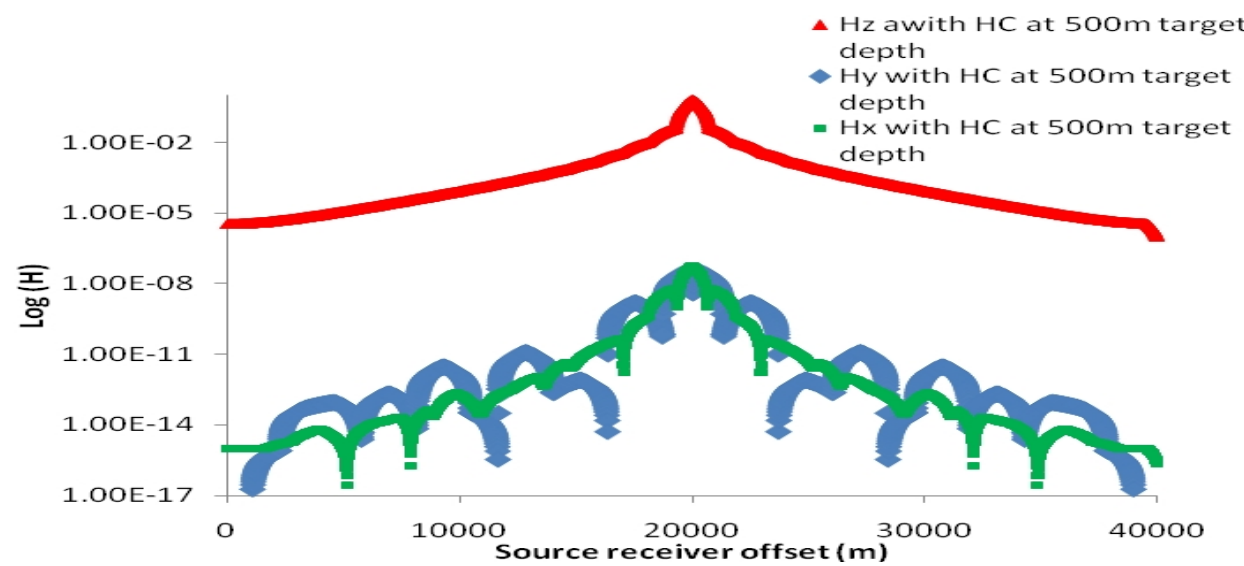

Fig. 4. Comparison of $\mathrm{H}$-field components $(\mathrm{Hx}, \mathrm{Hy}, \mathrm{Hz})$ response at500m target depth

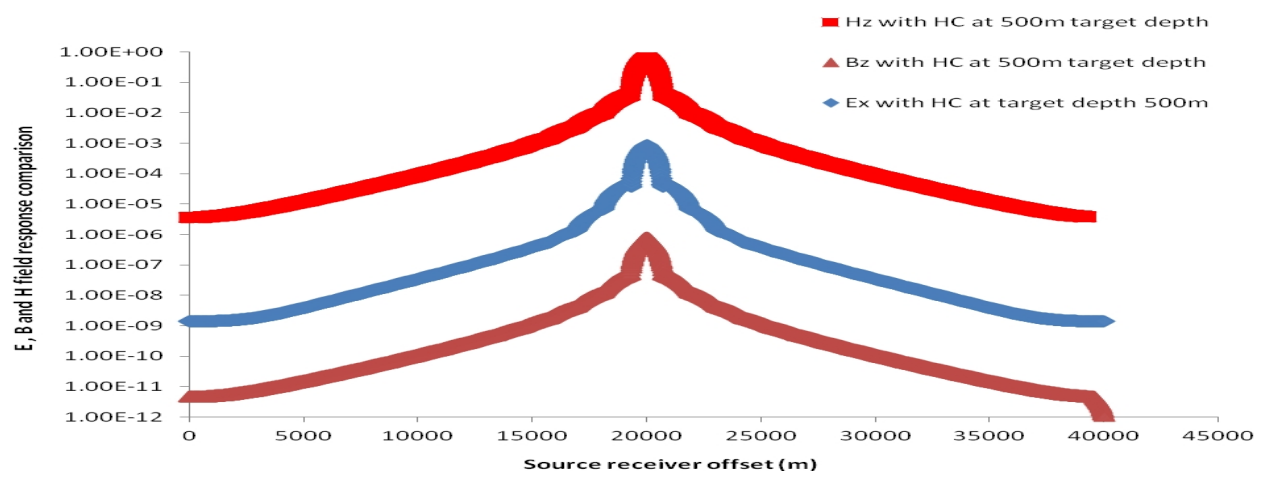

Fig. 5.Comparison of $\mathrm{Hz}, \mathrm{Ex}$ and $\mathrm{Bz}$ field response at 500m target depth

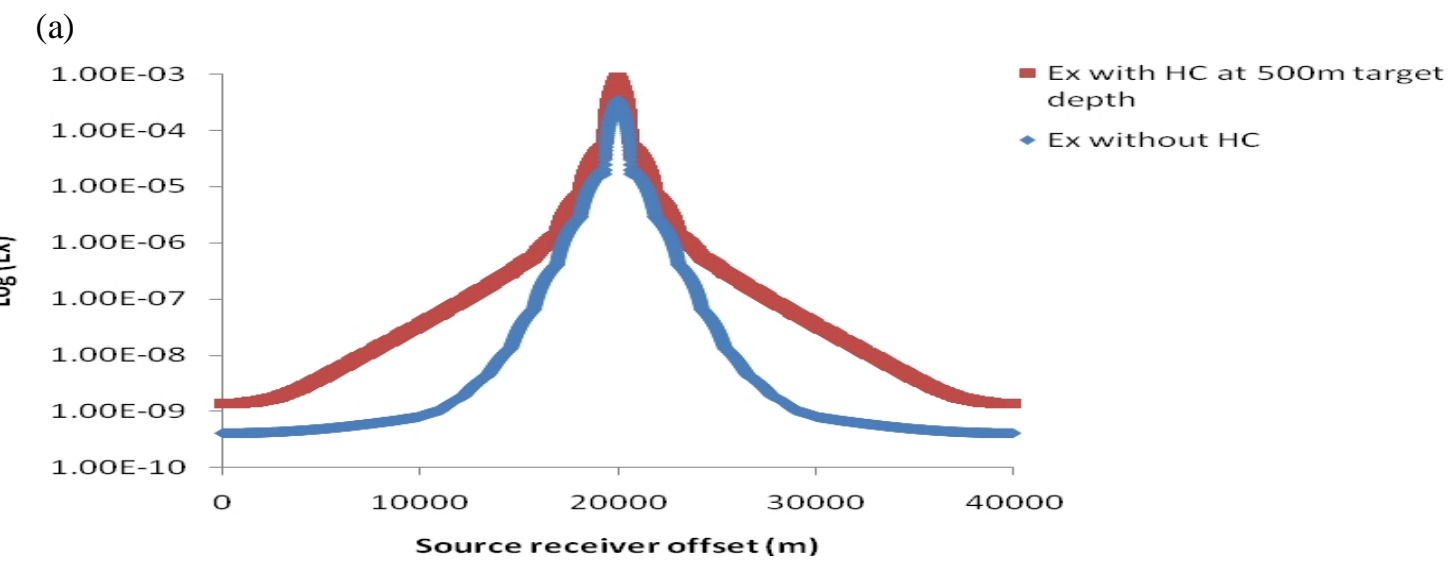

Nadeem Nasir et.al (Modeling of Antenna for Deep Target Hydrocarbon Exploration) 
(b)

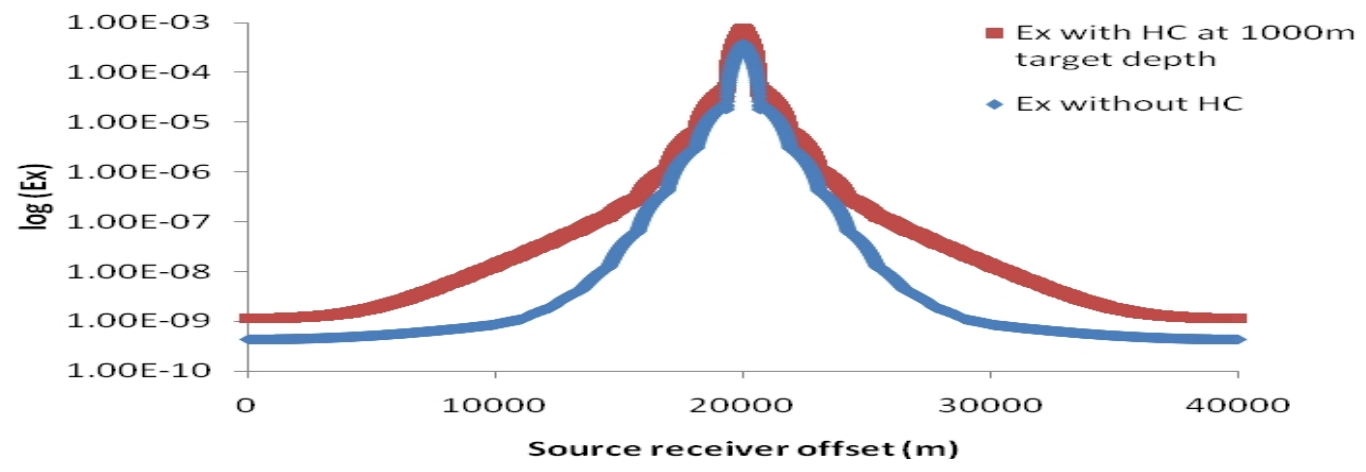

(c)

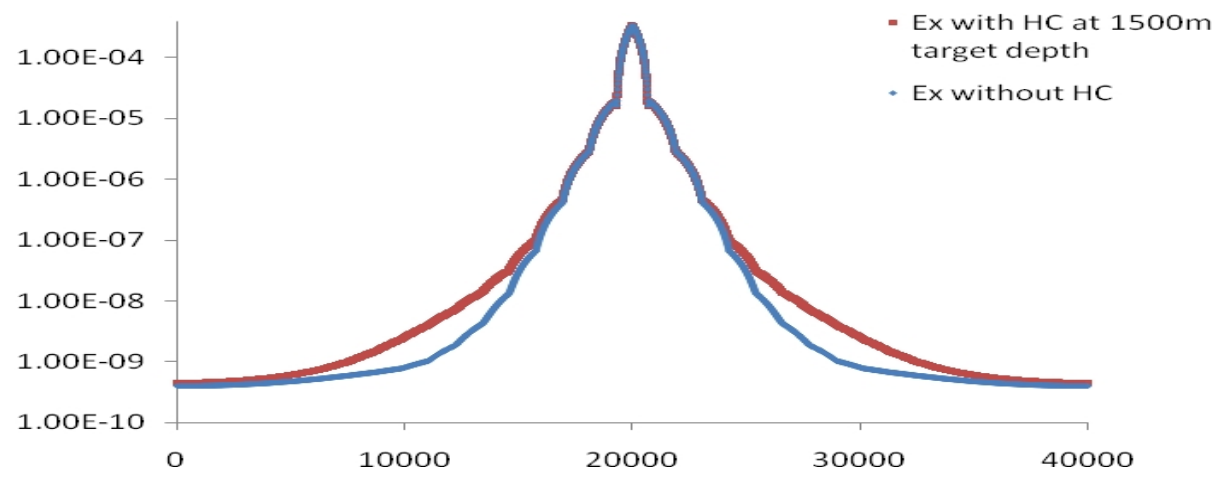

(d)

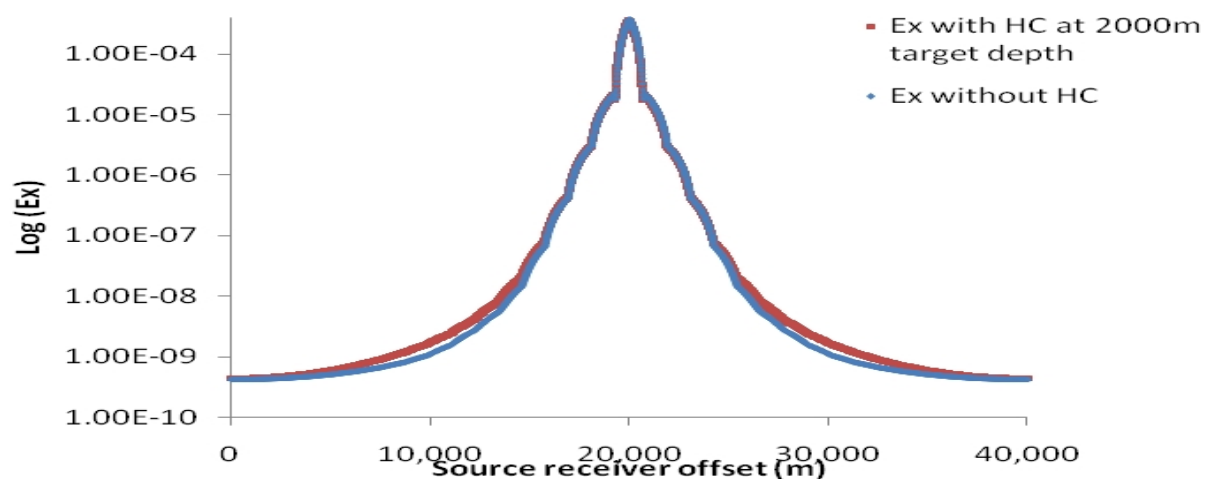

Fig. 6. Straight antenna Ex-field MVO with different target positions (a) $500 \mathrm{~m}$ (b) $750 \mathrm{~m}$ (c) $1000 \mathrm{~m}$ (d) $1250 \mathrm{~m}(\mathrm{e}) 1500 \mathrm{~m}(\mathrm{f}) 1750 \mathrm{~m}(\mathrm{~g}) 2000 \mathrm{~m}$

Straight antenna magnitude verses offset data was plotted by changing the target depth from $500 \mathrm{~m}$ until $2000 \mathrm{~m}$. Ex field response with and without hydrocarbon was measured to know the exact target depth which can be detected by the straight HED antenna in deep water. At 500m target depth straight antenna shows $70 \%$ resistivity contrast is given Figure 6 (a). Target depth was varied from $500 \mathrm{~m}$ to $750 \mathrm{~m}$ but the simulated model total layers depth keep constant by reducing the under burden depth. Ex field response decreases by increasing the target depth due to the skin depth. At $750 \mathrm{~m}$ target depth resistivity contrast drops to $57 \%$ is shown Figure 6b).Ex field response was measured until no hydrocarbon detected. It was analyzed that $42 \%, 26 \%$ and $12 \%$ difference with and without hydrocarbon at $1000 \mathrm{~m}, 1250 \mathrm{~m}$ and $1500 \mathrm{~m}$ respectively. Further target depth was decreased from $1500 \mathrm{~m}$ to $2000 \mathrm{~m}$ the difference between with and without hydrocarbon reservoir is $5 \%$ and $2 \%$ which is less than 10\%. Straight antenna can detect up to $1500 \mathrm{~m}$ target depth below the sea floor because drilling risk factor is involved below $10 \%$. 
(a)

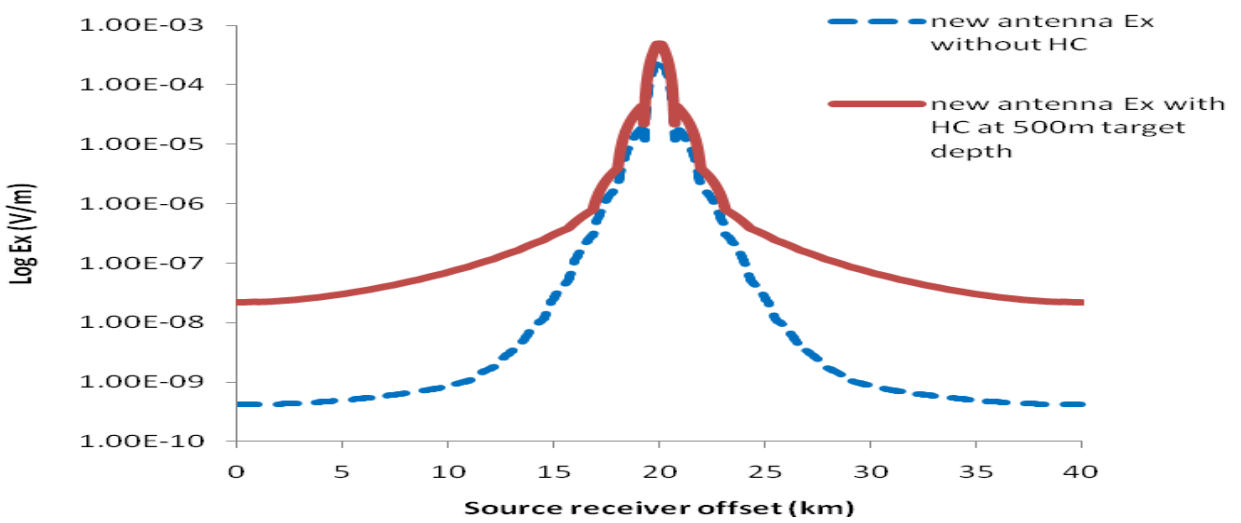

(b)

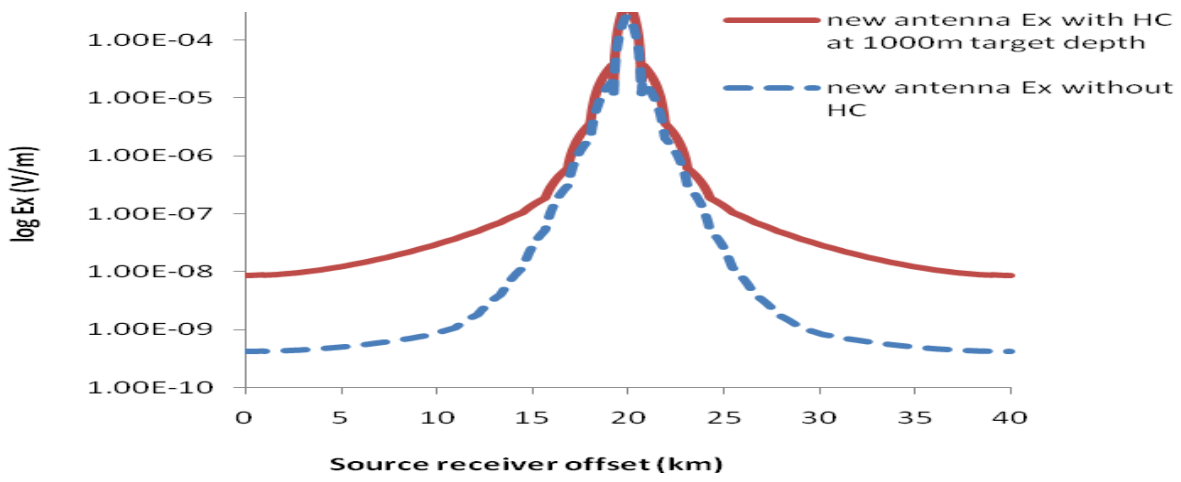

(c)

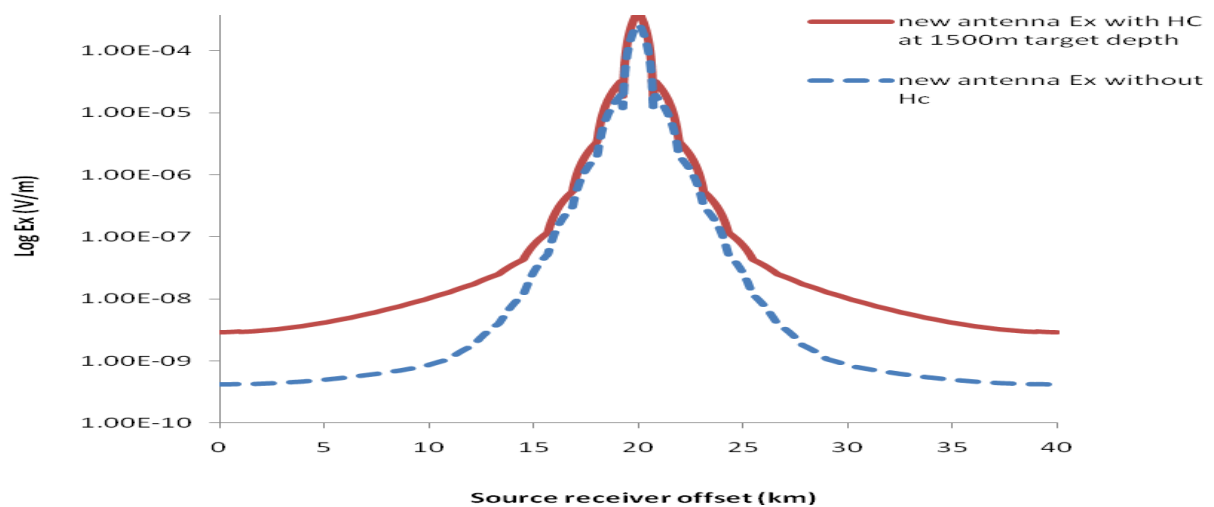

(d)

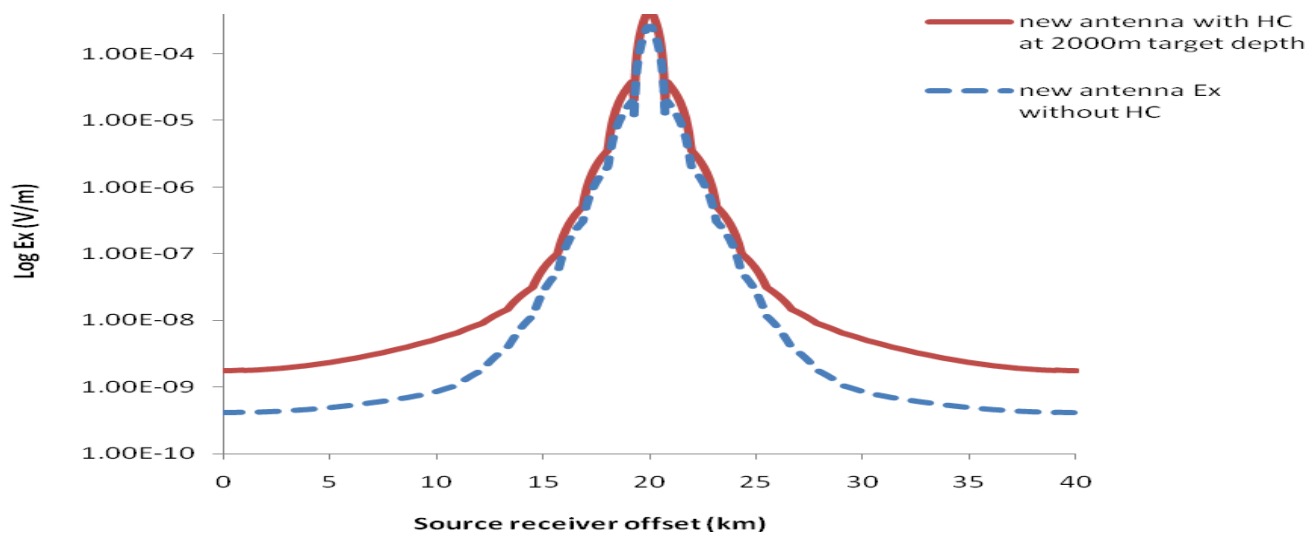

Nadeem Nasir et.al (Modeling of Antenna for Deep Target Hydrocarbon Exploration) 
(e)

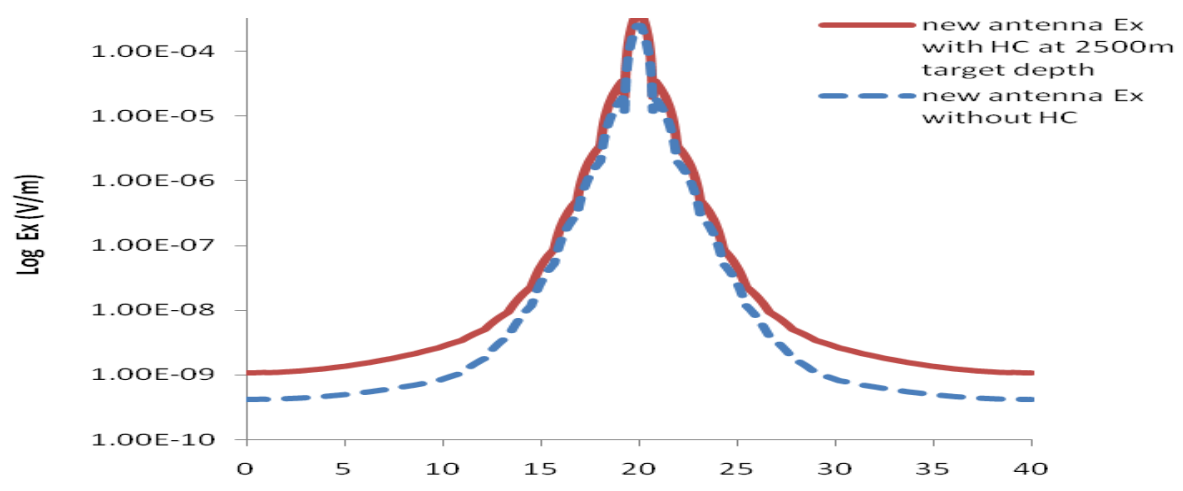

(f)

$(\mathrm{g})$
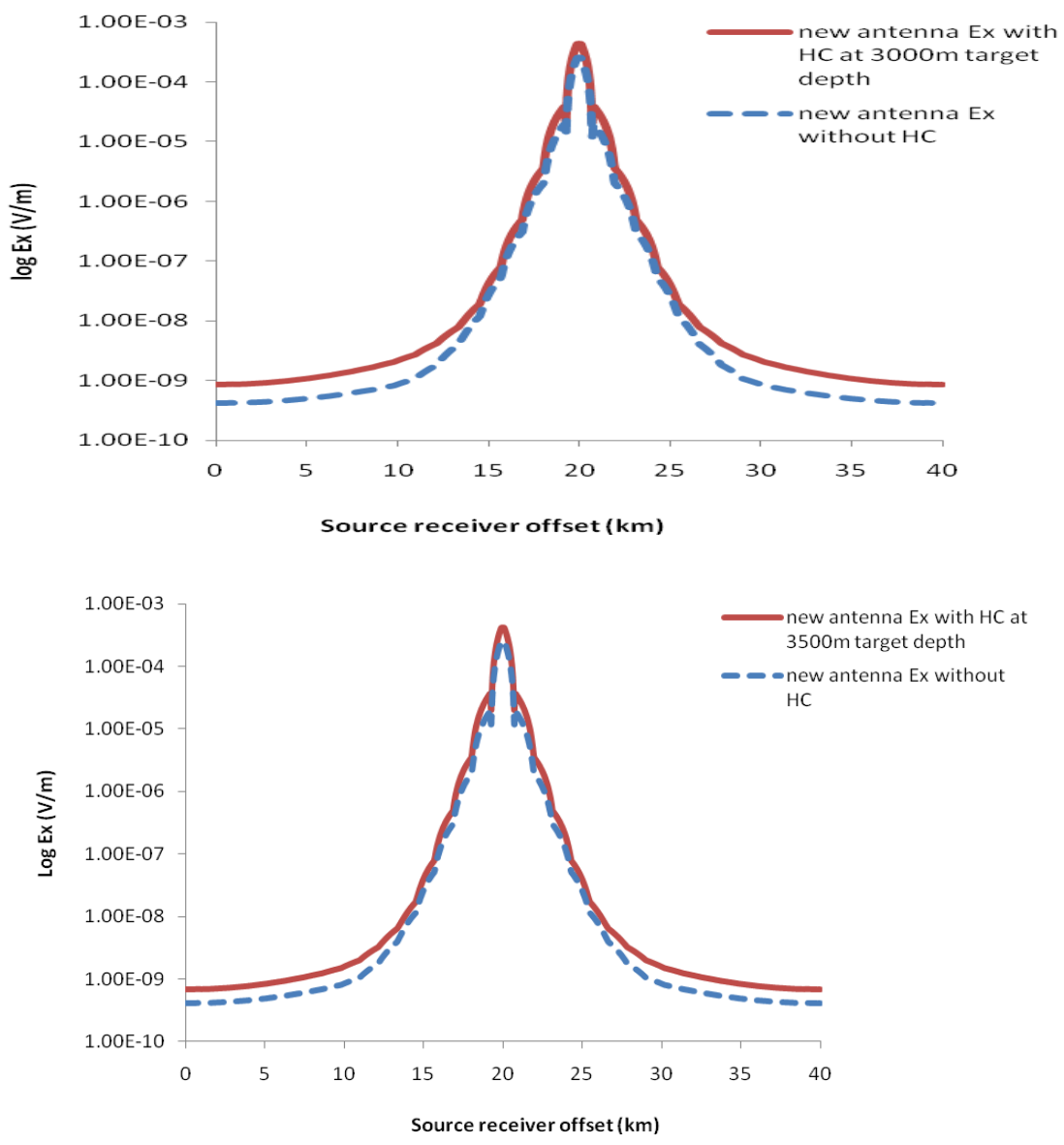

(h)

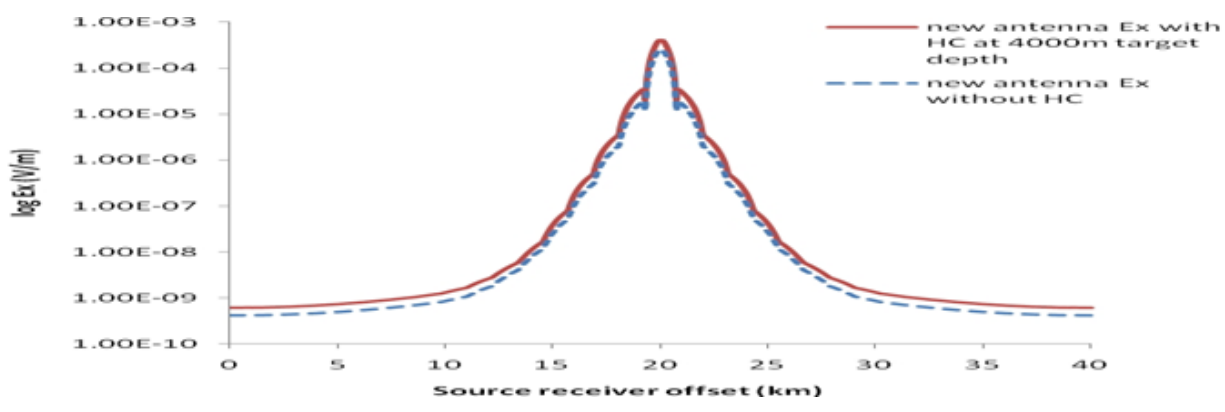

Nadeem Nasir et.al (Modeling of Antenna for Deep Target Hydrocarbon Exploration) 
(i)

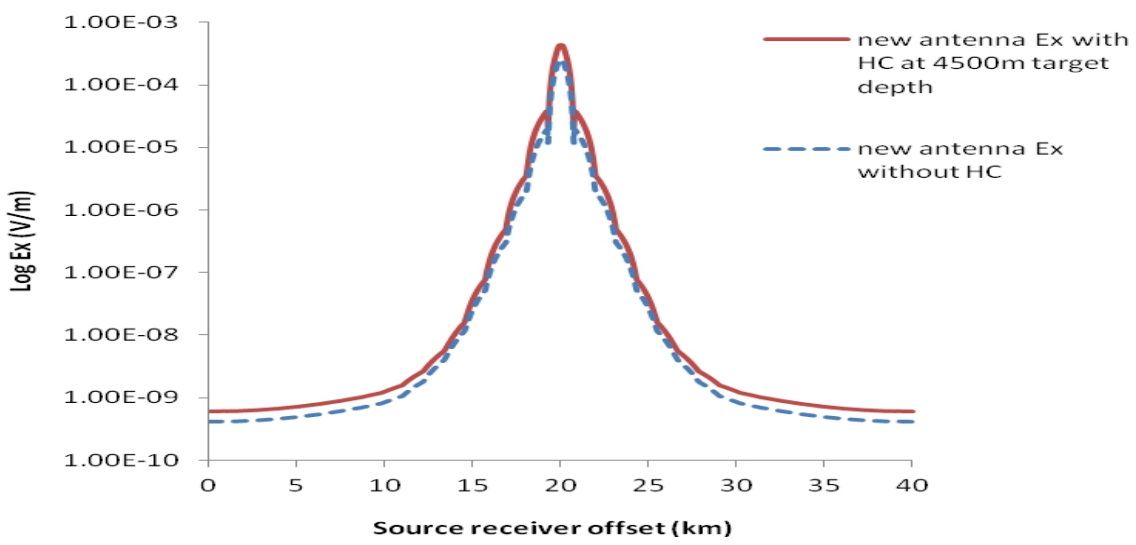

(j)

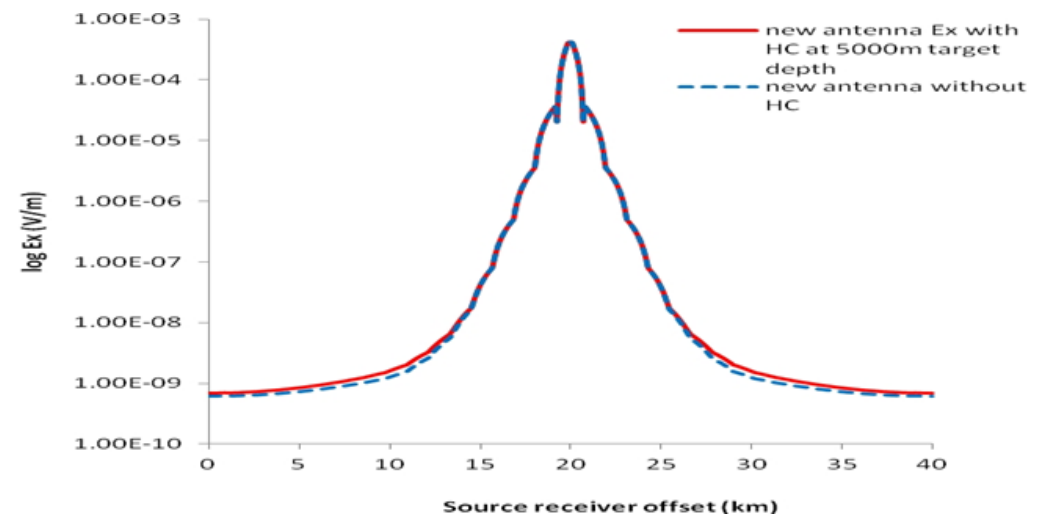

Fig. 7.New antenna Ex-field MVO with different target positions (a) $500 \mathrm{~m}$ (b) $1000 \mathrm{~m}$ (c) $1500 \mathrm{~m}$ (d) 2000 m (e) $2500 \mathrm{~m}$ (f) $3000 \mathrm{~m}$ (g) $3500 \mathrm{~m}$ (h) $4000 \mathrm{~m}$ (i) $4500 \mathrm{~m}$ (j) $5000 \mathrm{~m}$

$\mathrm{Hz}$ field response was also measured with straight antenna to get better delineation of hydrocarbon reservoir. Analysis between $\mathrm{Ex}$ and $\mathrm{Hz}$ at $500 \mathrm{~m}$ target depth shows $16 \%$ better delineation of hydrocarbon reservoir than Ex field response. At $1500 \mathrm{~m}$ target depth $\mathrm{Hz}$ field response was $12 \%$ higher than Ex field response. It was also conclude that $\mathrm{Hz}$ field shows $10 \%$ difference at $1750 \mathrm{~m}$ target depth. Magnetic field $\mathrm{Hz}$ component able to detect the hydrocarbon reservoir at $1750 \mathrm{~m}$ target depth where as Ex field response for $1500 \mathrm{~m}$ target depth respectively. Due to high $\mathrm{H}$-field strength it can detect $250 \mathrm{~m}$ extra depth than Ex field response is given Figure 7. Below $2000 \mathrm{~m}$ strong electromagnetic signal strength is required for deep target hydrocarbon detection.

\section{B. New antenna $M V O$ results}

Deep target detection is a challenging task in sea bed logging. Response from deep target hydrocarbon reservoir is very weak from straight antenna. The guided wave from the high resistive deep target has very low signal strength which is very difficult to predict the presence of hydrocarbon reservoir. A strong EM field is required and some modification of the HED antenna is highly needed by the oil and gas industry to ensure deep target. To enhance the signal strength and focus more electromagnetic (EM) waves for deep target new antenna was simulated with and without the presence of hydrocarbon reservoir to check the performance of new antenna. The proposed area of the seabed model which was simulated by using CST (computer simulation technology) EM studio based on Finite Integration Method (FIM). New antenna has the ability to focus electromagnetic waves.

New antenna was used to get the magnitude verses offset (MVO) response for 4000m target depth as given Figure 7. Solid lines indicate the response with presence of hydrocarbon where as dotted line represents without hydrocarbon response. It was analyzed that this new antenna shows $510 \%$ difference between the hydrocarbon or without hydrocarbon at $500 \mathrm{~m}$ target depth than 
straight antenna. This difference motivates to go for further target depth to predict the presence of high resistive layers hydrocarbon (HC). New antenna Ex field response shows $46 \%$ difference between with and without hydrocarbon resrvior at $4000 \mathrm{~m}$ target depth is given Figure 8 . This new antenna shows $12 \%$ difference at $4250 \mathrm{~m}$ target depth in deep water and can be used to reduce the drilling risk factor for oil and gas industry until $4250 \mathrm{~m}$ target depth. Comparison of straight and new antenna is shown in Table 3 and Table 4 respectively. the presence of high resistive layers hydrocarbon (HC). New antenna Ex field response shows $46 \%$ difference between with and without hydrocarbon resrvior at $4000 \mathrm{~m}$ target depth is given Figure 8 . This new antenna shows $12 \%$ difference at $4250 \mathrm{~m}$ target depth in deep water and can be used to reduce the drilling risk factor for oil and gas industry until $4250 \mathrm{~m}$ target depth. Comparison of straight and new antenna is shown in Table 3 and Table 4 respectively.

(a)

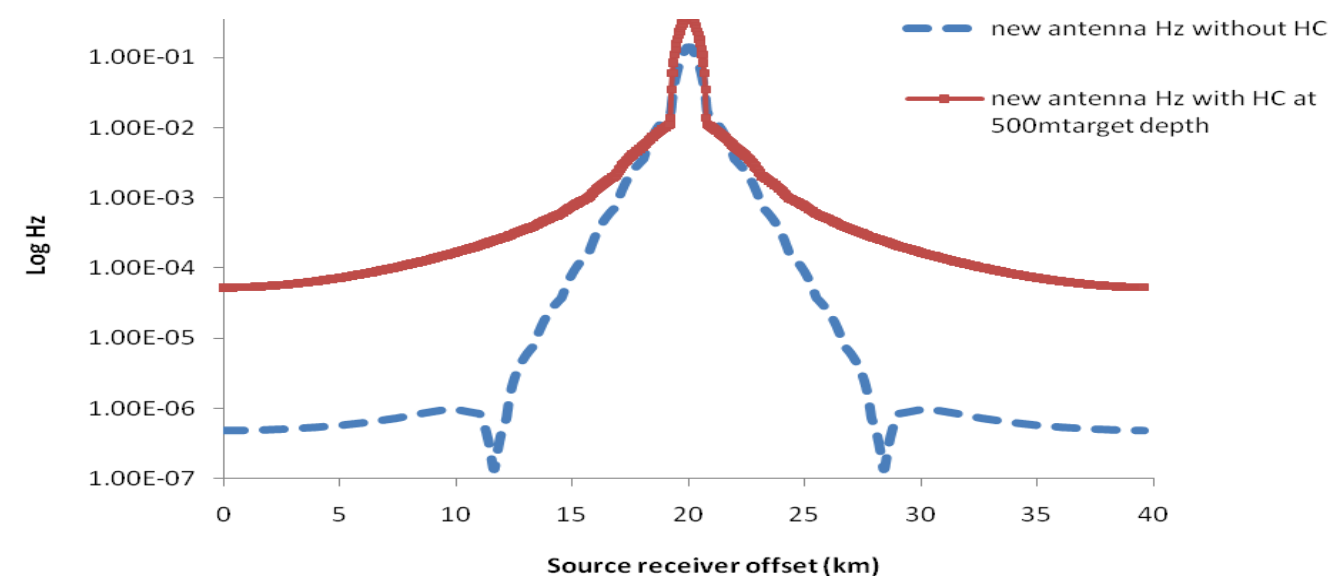

(b)

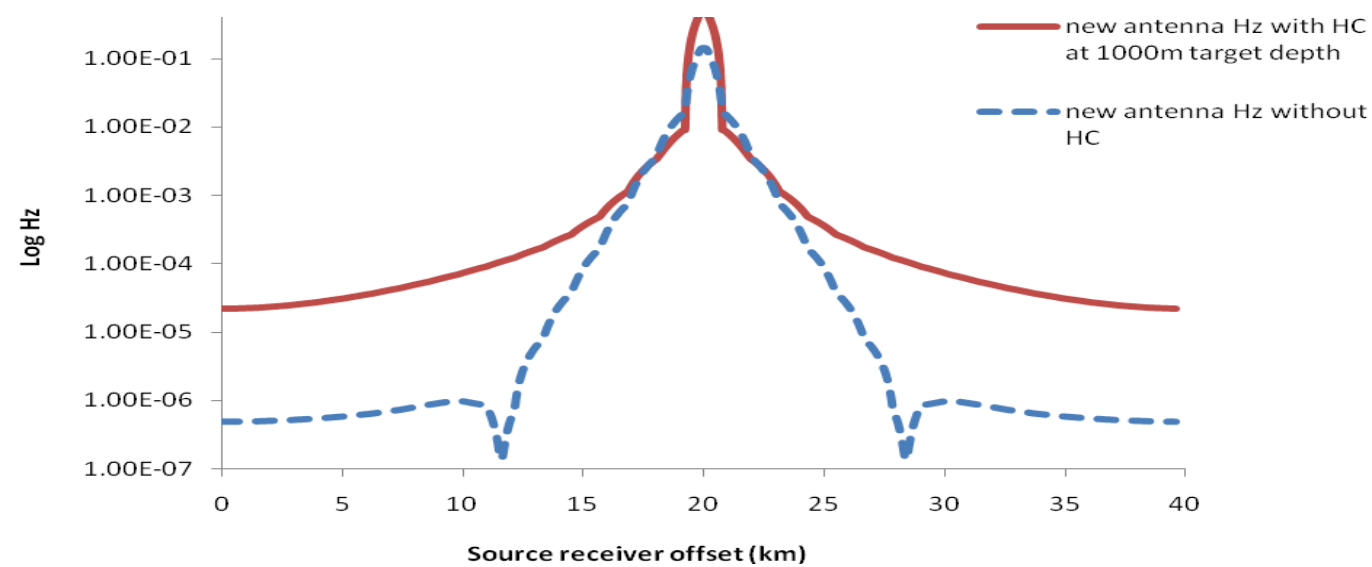

(c)

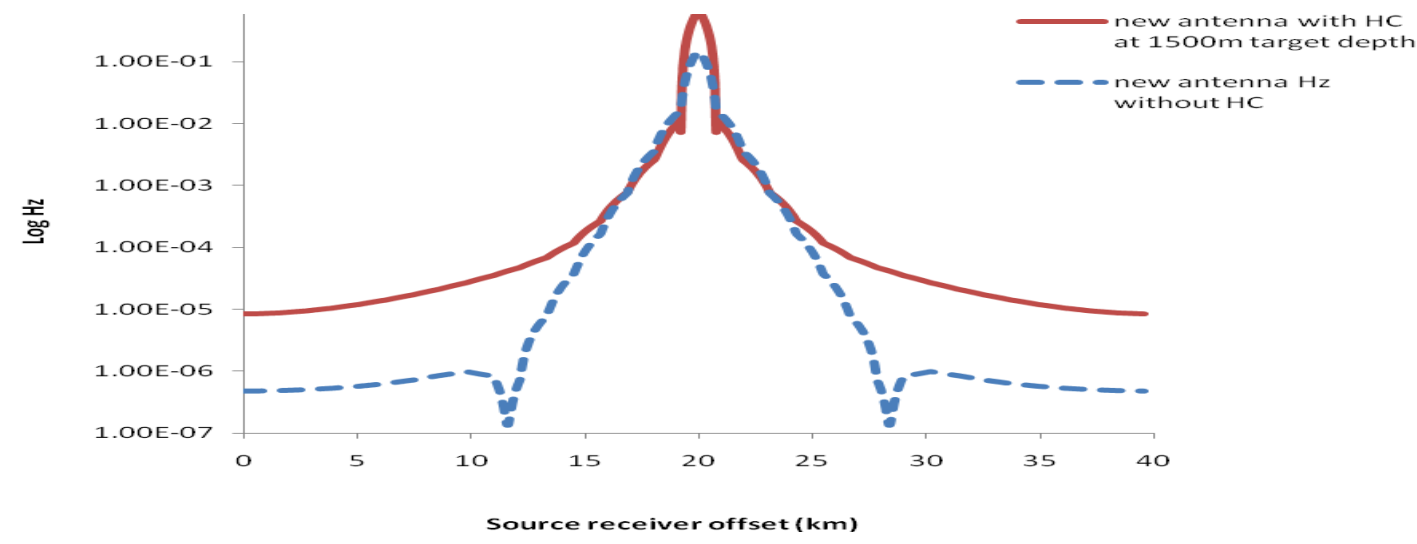


(d)

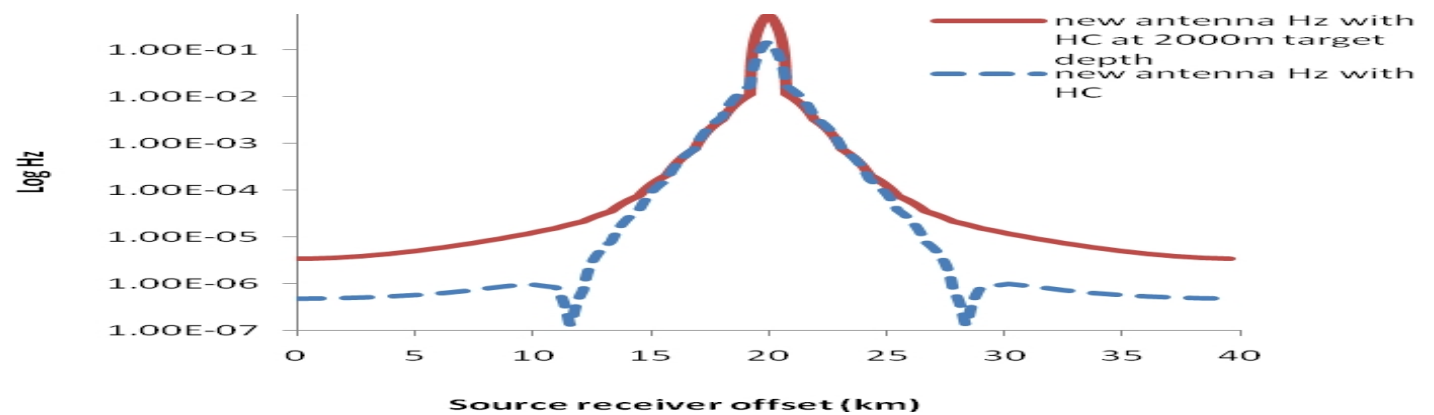

(e)

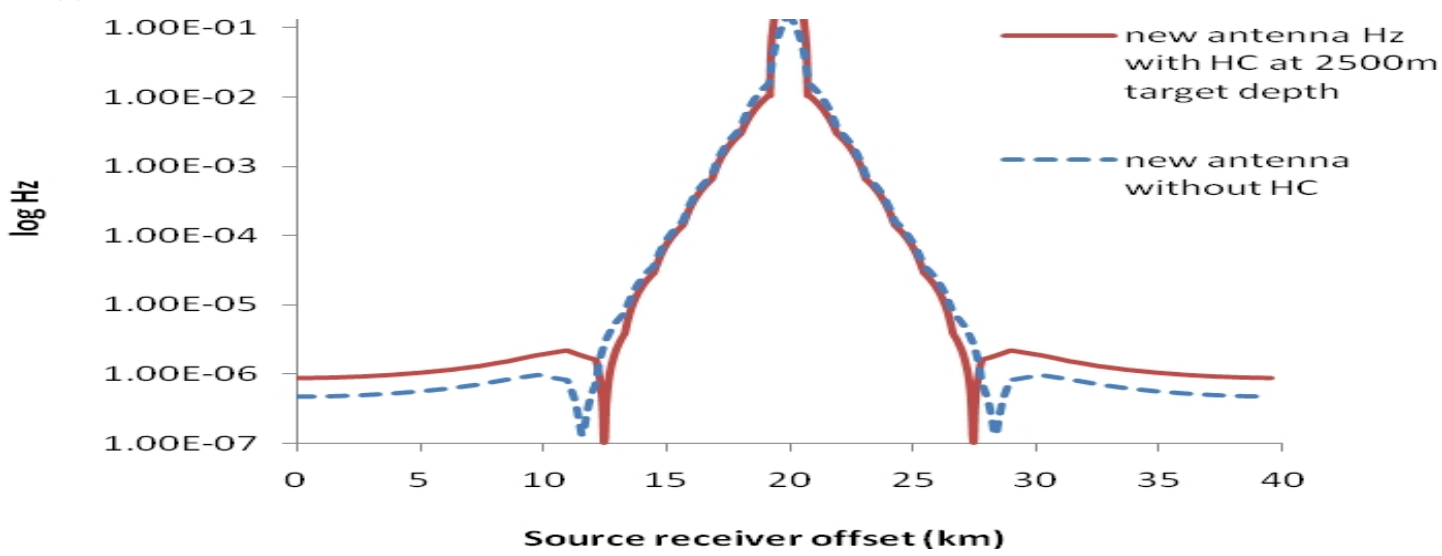

(f)

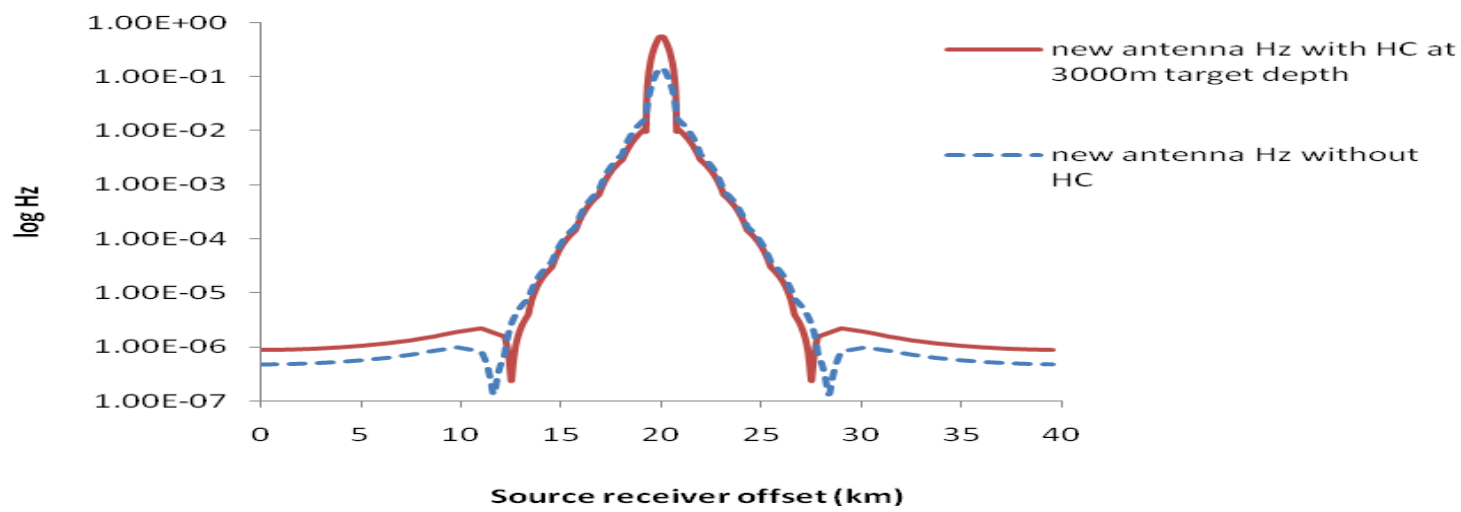

(g)

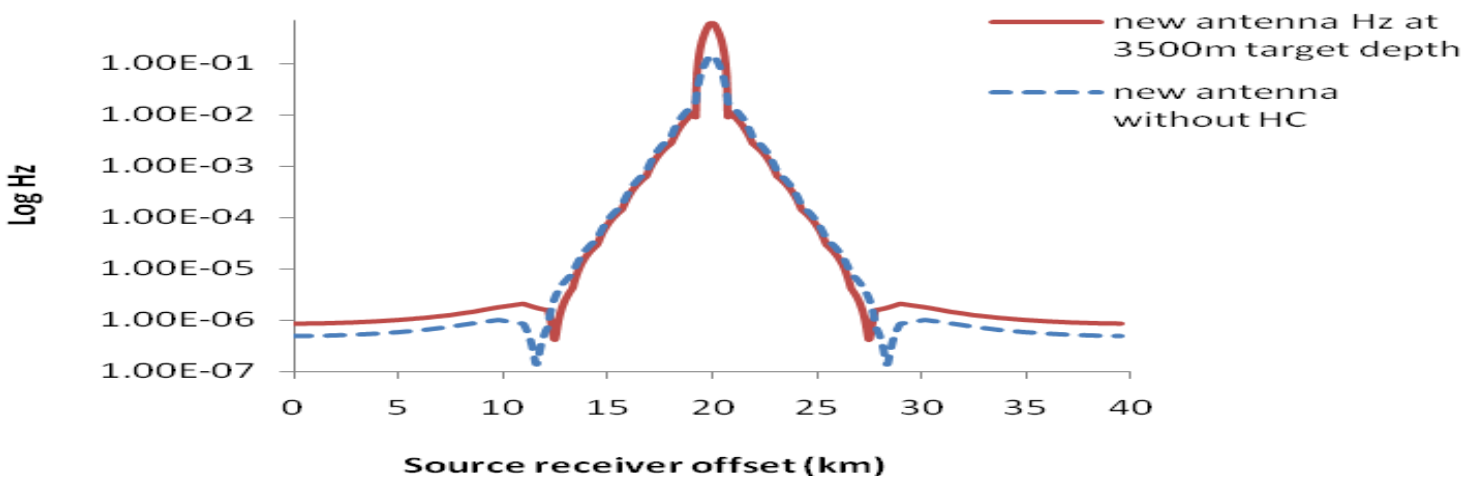


(h)

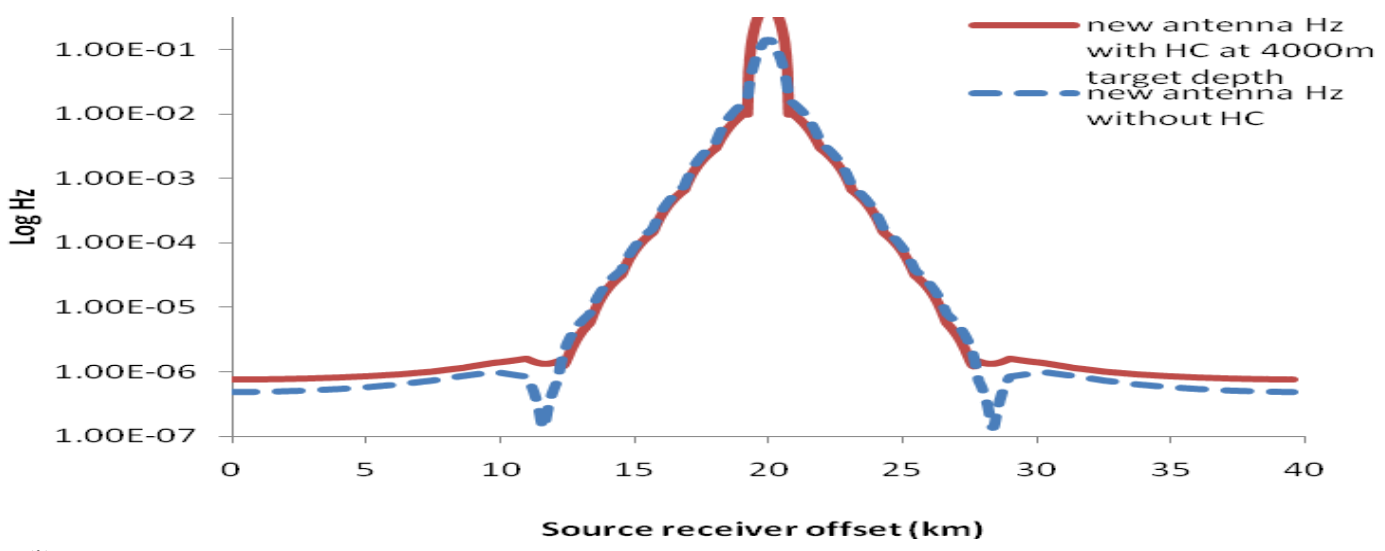

(i)

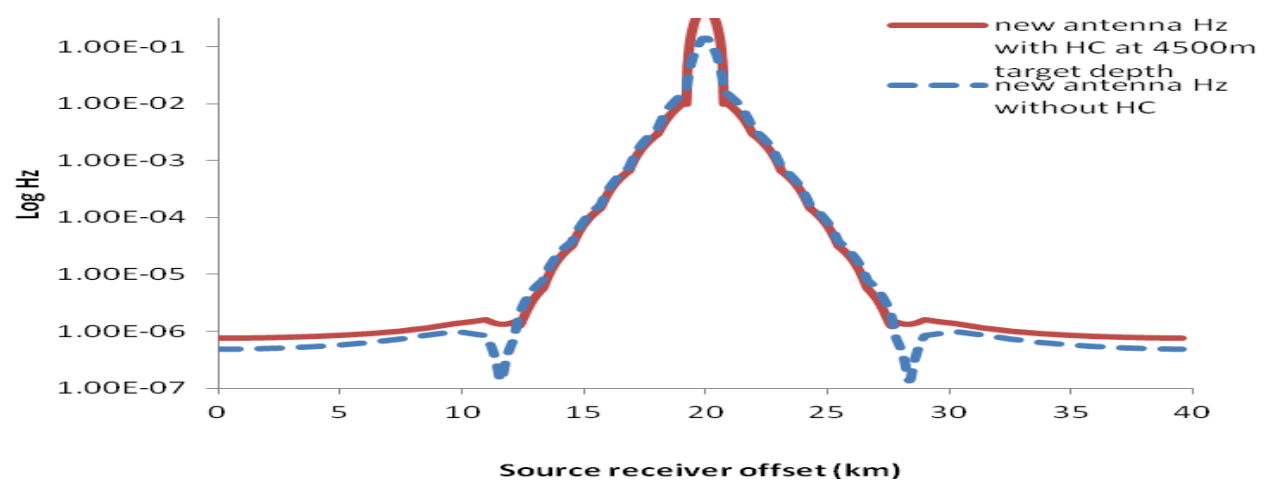

(j)

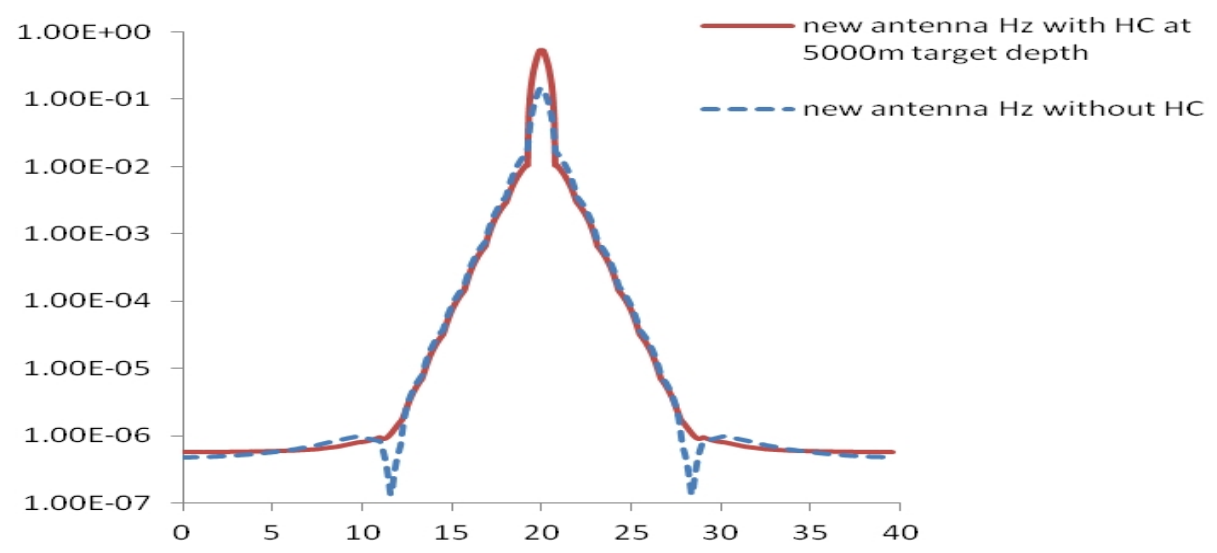

Source receiver offset $(\mathrm{km})$

Fig. 8. New antenna Hz-field MVO with different target positions (a) $500 \mathrm{~m}$ (b) $1000 \mathrm{~m}$ (c) $1500 \mathrm{~m}$ (d) $2000 \mathrm{~m}$ (e) $2500 \mathrm{~m}$ (f) $3000 \mathrm{~m} \mathrm{(g)} 3500 \mathrm{~m}$ (h) $4000 \mathrm{~m}$ (i) $4500 \mathrm{~m}$ (j) $5000 \mathrm{~m}$.

New antenna $\mathrm{Hz}$ magnitude verses offset comparison with different target depth is given Figure 8. Solid lines in MVO plot represent hydrocarbon response where as dotted lines without hydrocarbon reservoir. For near offset less than $3 \mathrm{~km}$ direct wave dominate and hydrocarbon reservoir presence cannot be predicted. Greater than $3 \mathrm{~km}$ offset in deepwater guided response dominate the direct wave's response. Due to this reason greater than $3 \mathrm{~km}$ offset can predict about the presence of hydrocarbon reservoir. Magnetic field response curve width is more as compared to electric field because magnetic field decreases 1/R2 where as electric field 1/R3 ( $R$ is the radial distance from the center of dipole to the measurement point) [26]. At $500 \mathrm{~m}$ target depth new antenna shows $540 \% \mathrm{~Hz}$ field strength than without hydrocarbon reservoir. As the target depth 
increases the $\mathrm{Hz}$ field strength decreases due to the skin depth effect. At 4250m target depth Ex response was $12 \%$ where as $\mathrm{Hz} 16 \%$ with new antenna design and $\mathrm{Hz}$ component able to delineate deep target better than Ex component. Analysis of new antenna results reveals that it can be used to detect deep target up to $4500 \mathrm{~m}$ target depth below the sea floor in deep water.

Table 3. Straight antenna Exand $\mathrm{Hz}$ field response \% difference comparison at different target depth with and without $\mathrm{HC}$

\begin{tabular}{ccc}
\hline $\begin{array}{c}\text { Target } \\
\text { Depth (m) }\end{array}$ & $\begin{array}{c}\text { Straight antenna \% difference in Ex } \\
\text { field with and without HC at different } \\
\text { target depth }\end{array}$ & $\begin{array}{c}\text { Straight antenna \% difference in } \\
\text { Hz field with and without HC at } \\
\text { different target depth }\end{array}$ \\
\hline 700 & 57 & 84 \\
\hline 750 & 42 & 76 \\
\hline 1000 & 26 & 58 \\
\hline 1250 & 12 & 40 \\
\hline 1500 & 5 & 22 \\
\hline 1750 & 2 & 5 \\
\hline 2000 & & 5 \\
\hline
\end{tabular}

Table 4. At different target depth with and without $\mathrm{HC}$

\begin{tabular}{ccc}
\hline Target Depth (m) & $\begin{array}{c}\text { New antenna \% difference in Ex field } \\
\text { with and without HC at different target } \\
\text { depth }\end{array}$ & $\begin{array}{c}\text { New antenna } \\
\text { difference in Hz field with } \\
\text { and without HC at different } \\
\text { target depth }\end{array}$ \\
\hline 1000 & 329 & 335 \\
\hline 1500 & 298 & 305 \\
\hline 2000 & 221 & 229 \\
\hline 2500 & 160 & 168 \\
\hline 3000 & 107 & 114 \\
\hline 3500 & 64 & 68 \\
\hline 4000 & 46 & 51 \\
\hline 4250 & 12 & 16 \\
\hline 4500 & 2 & 5 \\
\hline
\end{tabular}

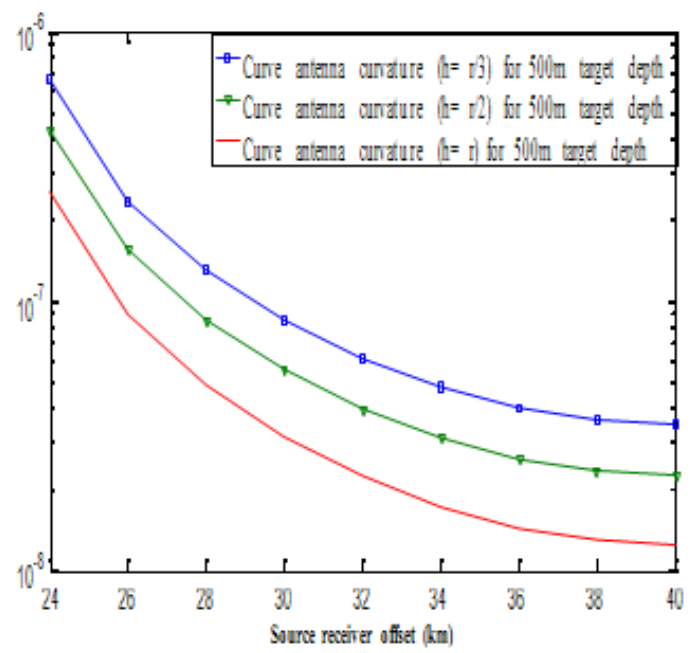

Fig. 9. Numerical model with straight antenna used for sea bed logging

Different curvatures were compared at $500 \mathrm{~m}$ target depth in deep water environment to know which curvature gave higher signal strength with the presence of hydrocarbon reservoir. From results it was analyzed that curvature $h=r / 3$ gave higher magnitude verses offset response as given in Figure 9. 


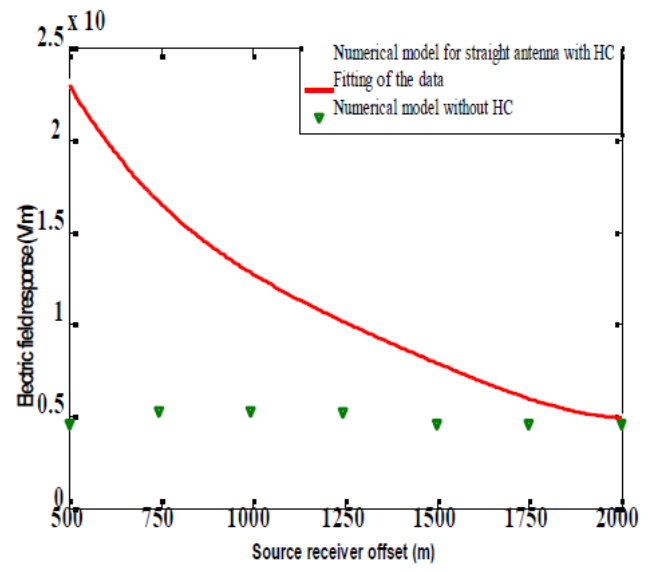

Fig. 10. Numerical model with straight antenna used for sea bed logging

\section{Numerical model for straight and new antenna for deep target in deep water environment}

Numerical model is a very important to know the location hydrocarbon in sea bed logging. It can provide the information about the target depth at which target depth the electromagnetic wave signal provide information about hydrocarbon reservoir. Regression analysis was done for numerical model of electric field data at different target depths. Nonlinear regression technique is used to get the best fit mathematical function for input data. Simulated data for different target depth is used for numerical model for straight and new antenna data. Guided wave response data at different target depth is used for numerical model. Data fitting tool is used to fit the sea bed logging data for various target depths. Target depth $500 \mathrm{~m}$ to $2000 \mathrm{~m}$ target depth fitting of our proposed sea bed model data fitting.

Guided wave response is used for fitting the data. More than 800 data points are used for data fitting for survey area of $40 \mathrm{kmx} 40 \mathrm{~km}$. These equations were used for numerical model. The numerical model for the straight antenna is given Figure 10. The electromagnetic field response decreases with the inverse square of the distance between the source/receiver offset. From these equations, the electric field response was calculated at far offset. At each target depth, the electric field response was used to plot the numerical model for the straight antenna. Circles represent the numerical model of the straight antenna with different target depths where as triangles without a hydrocarbon reservoir. To know the numerical model behavior again, data fitting was used which is represented by the solid line in the model. From this fitting, the general equation for the straight antenna numerical model was obtained as given (5).

$$
E=\exp \left(\text { cons }+\alpha x+\beta x^{2}\right)
$$

Where $\mathrm{E}$ is the electric field response (Ex), $\mathrm{x}$ is the target depth where as constants $\alpha, \beta$ represent the decay rate of guided wave from hydrocarbon reservoir and direct wave response. Decay rate of guided wave response $(1.57 \times 10-7)$ is slower than the direct wave response $(-1.41 \times 10-4)$ [27]. From this numerical model, the electric field response at different target depths can be calculated and the presence of the hydrocarbon reservoir can be predicted. At different target depths, the electric field response is given in Table 6 . With the numerical model of the straight antenna, by changing the target depth it ensures that this antenna can be used to detect the $1750 \mathrm{~m}$ target depth. Estimated electric field response with this numerical model equation also proves the accuracy of this model because at all target depths response is within the range of the with and without hydrocarbon reservoir model.

The numerical model for the curved antenna with the curvature $h=r / 3$ was plotted with the help of data fit equations for different target depths andis given (Figure11).

$$
E=\exp \left(\text { cons }+\alpha x+\beta x^{2}\right)
$$




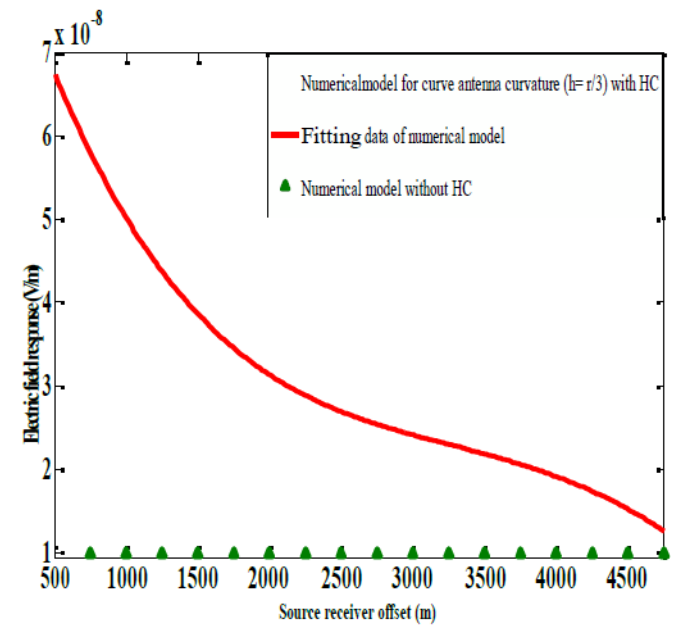

Fig. 11. Numerical model with antenna curvature $h=r / 3$ with different target depth

Table 5. Straight antenna E field response calculation at different target depth with the help of numerical model

\begin{tabular}{cc}
\hline Target depth & $\begin{array}{c}\text { New antenna E field response with target depth } \\
(\mathbf{V} / \mathbf{m})\end{array}$ \\
\hline 510 & $2.24 \times 10-9$ \\
\hline 610 & $1.96 \times 10-9$ \\
\hline 710 & $1.76 \times 10-9$ \\
\hline 810 & $1.56 \times 10-9$ \\
\hline 910 & $1.41 \times 10-9$ \\
\hline 1110 & $1.25 \times 10-9$ \\
\hline 1210 & $1.11 \times 10-9$ \\
\hline 1310 & $1.01 \times 10-9$ \\
\hline 1410 & $8.34 \times 10-10$ \\
\hline 1510 & $7.53 \times 10-10$ \\
\hline Without hydrocarbon & $4.55 \times 10-10$ \\
\hline
\end{tabular}

Table 6. New antenna E field response calculation at different target depth with the help of numerical model

\begin{tabular}{cc}
\hline Target depth & $\begin{array}{c}\text { New antenna E field response with target depth } \\
(\mathbf{V} / \mathbf{m})\end{array}$ \\
\hline 510 & $6.5 \times 10-8$ \\
\hline 975 & $5.2 \times 10-8$ \\
\hline 1450 & $4.1 \times 10-8$ \\
\hline 1925 & $3.4 \times 10-8$ \\
\hline 2400 & $2.8 \times 10-8$ \\
\hline 2875 & $2.4 \times 10-8$ \\
\hline 3350 & $2.1 \times 10-8$ \\
\hline 3825 & $1.9 \times 10-8$ \\
\hline 4300 & $1.7 \times 10-8$ \\
\hline 4775 & $1.6 \times 10-8$ \\
\hline Without hydrocarbon & $1.5 \times 10-8$ \\
\hline
\end{tabular}

Analytical results show that scattered field from hydrocarbon reservoir takes the form of exponential decay function [27]. Scattered field from hydrocarbon reservoir decay slower than the direct wave response. The equation shows the electromagnetic field behavior with target depths where $\mathrm{x}$ is the target depth and $\mathrm{E}$ the electric field response with the corresponding target depth. In equation, 5.5 Constants $\alpha, \beta$ represents the decay rate of guided and direct wave from hydrocarbon reservoir. Decay rate of guided wave response with curve antenna curvature $h=r / 3$ $(0.54 \times 10-7)$ is slower than straight antenna $(-1.41 \times 10-4)$. The decay rate is $66 \%$ slower than straight antenna, which indicates this antenna can detect further deeper target. Different target depth 
equations were plotted to get the numerical model, and it was observed that, the curved antenna with the curvature $\mathrm{h}=\mathrm{r} / 3$ can detect up to a $4.5 \mathrm{~km}$ target depth. Numerical model (Equations 5,6 ) was used to validate the electric field response for straight antenna and new antenna design for deep hydrocarbon target. At different target depths the electric field response from numerical model equation was within the range of electric field response as got from the simulated results. Straight and new antenna electric field response is given (Table 5, 6) respectively.

\section{Conclusion.}

Electromagnetic field components response with hydrocarbon reservoir at $500 \mathrm{~m}$ target depth was done which shows that Ex and $\mathrm{Hz}$ components shows better delineation than other components. Ex field response for new antenna shows 329\% resistivity contrast at target depth of $1000 \mathrm{~m}$ where as straight antenna showed $70 \%$ resistivity contrast at same target depth. $\mathrm{Hz}$ field shows $355 \%$ resistivity contrast where as straight antenna shows $86 \%$. From these results it was analyzed that $\mathrm{Hz}$ field shows better delineation for hydrocarbon detection. It was also observed that at frequency of $0.125 \mathrm{~Hz}$, new antenna gave $46 \%$ better delineation of hydrocarbon at $4000 \mathrm{~m}$ target depth. Numerical modeling was done to know the exact target depth at which this new antenna can detect in deep water environment. It was observed that new antenna can detect $4.5 \mathrm{~km}$ target depth.

\section{References}

[1] L . M acGregor, \& M.Sinha, "Use of marine controlled-source electromagnetic sounding for sub-basalt exploration "Geophysical Prospecting vol. 48,1091-1106. (2000).

[2] B.Tossman, D. Thayer, \& W. Swartz, "An underwater towed electromagnetic source for geophysical exploration". IEEE Journal of Oceanic Engineering vol. 4, pp. 84-89. (1979).

[3] S. Johansen, et al, "Subsurface hydrocarbons detected by electromagnetic sounding," first break vol. 23, pp.31-36, (2005).

[4] Yahya N., Akhtar M.N., Nasir N., Shafie A., Jabeli M.S., and Koziol K., "CNT Fibres/Aluminium$\mathrm{NiZnFe}_{2} \mathrm{O}_{4}$ Based EM Transmitter for Improved Magnitude vs. Offset (MVO) in a Scaled Marine Environment", Journal of Nanoscience and Nanotechnology, Accepted Article in press. 2011.

[5] Yahya N., Akhtar M.N., Nasir N., Daud H., and Narahari M., "Forward Modeling of Seabed Logging by Finite Integration (FI) and Finite Element (FE) Methods" DSL 2011 Purtagal. Accepted Article in press. 2011.

[6] Yahya N., Kashif M., Daud H., Zaid H.M., Shafie A., Nasir N., and See A.,"Fabrication and Characterization of Y3.0-XLaXFe5O12 - PVA Composite as EM Waves Detector" International Journal of Basic \& Applied Sciences IJBAS Vol: 9 No: 9 131-134.

[7] N.Nasir, N.Yahya, M.N.Akhtar, M.Kashif, A.Shafie, H.Daud, and H.M.Zaid, "Magnitude verses offset study with EM transmitter in different resistive medium," J.Applied.Sci, vol 1, (2011).

[8] M.N.Akhtar, N.Yahya, H.Daud, A.Shafie, H.M.Zaid, M.Kashif, and N.Nasir, "Development of EM wave guide amplifier potentially used for seabed logging", J.Applied.Sci, vol 1, (2011).

[9] M. Unsworth, "New developments in conventional hydro carbon exploration with electromagnetic methods," CSEG Recorder, pp.34-38, (2005).

[10]P. Clemmow, "The theory of electromagnetic waves in a simple Vanisotropic medium," Proc. IEEE vol.110, pp.101- 106, (1963).

[11]FN. Kong., H. Weterdahl, Ellingsrud. S., Eidesmo. T., and Johansen S., "A possible direct hydrocarbon indicator for deep sea prospects using EM energy", Oil and Gas Journal. 100, 30-38, (2002).

[12]C.S. Cox, S.C. Constable, A.D. Chave, S.C.Webb,"Controlled source electromagnetic sounding of the oceanic lithosphere," Nature vol. 320, pp. 52-54, (1986).

[13] M.C.Sinha, P.D. Patel, M.J. Unsworth, T.R.E. Owen, and M.G.R.MacCormack,"Anactive source electromagnetic sounding system for marine use," Marine Geophysical Research,vol. 12, pp. 29-68, (1990).

[14]P. D. Young and C. S. Cox , "Electromagnetic active source sounding near the East Pacific Rise," Geophysical Research Letters, vol. 8, pp.1043- 1046, (1981).

[15]E. Um, \& D. Alumbaugh, "On the physics of the marinecontrolled - source electromagnetic method," geophysics vol.72, (2007).

[16] S. C Webb, S. C. Constable, C. S. Cox and T. K Deaton, "A Seafloor Electric Field Instrument," Journal of Geomagnetism and Geoelectricity, vol. 37, pp.1115-1129, (1985). 
[17] A.D Chave, S.C. Constable and R. N. Edwards, "Electrical Exploration Methods For The Seafloor Electromagnetic Methods in Applied Geophysics," SEG, pp. 931-966, (1982).

[18] T.Eidesmo, S.Ellingsrud, L.M.Mac Gregor, S.C.Constable, M.C.Sinha, S.Johansen, F.N.Kong, H.Westerdahl,"SeaBed Logging (SBL), a new method for remote and direct identification of filled layers in deepwater areas using controlled source electromagnetic sounding," First Break, vol.20, pp.144$152,(2002)$. 